\title{
Discussion: Morning Session
}

Chairman, Professor E. AdL ER. We shall start now with the discussion on the papers we have heard so far.

Professor BeLLER (Israel). I have very much enjoyed the papers given this morning, presenting the different aspects of deformity of the spine, particularly in children and adolescents.

In order to confuse the issue, I should like to add an additional aspect that I have come across in the past years. This refers to adolescents between the ages of $\mathrm{I} 4$ and $\mathrm{I} 8$. The major complaint was of progressive scoliosis of the thoraco-lumbar spine with occasional pain, which is unusual in a progressive scoliosis. First of all, on investigating the patients carefully and from the parents' information, we could ascertain that there was a history of a mild trauma, like falling off a bicycle or jumping into a swimming-pool, or some injury due to exercise. And, on careful neurological examination, we found some minor changes which were limited to one or several spinal lumbar roots. This led us to search for a diagnosis on six cases, and on myelography we found in all of them large filling defects of the lumbar spine mainly between $\mathrm{L}_{5}$ and $\mathrm{S}_{1}$, most probably due to disc lesions, which were confirmed at operation. After removal of the discs, five out of six made an excellent recovery and the sixth one-a girl of I6-was markedly improved.

I would like to add this additional aspect to the problem of deformity of the spine in children and adolescents.

Dr. Meinecke (Germany). I have one question to ask Dr. Bedbrook. We saw the braces you are using: do you not fear pressure sores from the braces?

Dr. BeDbRook (Australia). The answer is-no, we do not see any pressure sores. But, these children are very carefully nursed. This child actually wears his brace for about 16 hours out of the 24, and when he is not in the brace he is resting supine or prone with proper postural control. This brace is, therefore, used when the child is standing or sitting. I realise that this work is only in its infancy at the moment and it has to be done with very careful bracemakers, and we have got to supervise it very carefully.

Mr. Chairman, I have one question I would like to direct to $\mathrm{Mr}$. Harris, please. I would like to ask whether, in that operated case of the cauda equina lesion where he found arachnoiditis, any recovery occurred subsequent to his surgery? And I would also like to comment on the fact that anatomically the cauda equina and the cord occupy only about 15 per cent. of the neural canal. In some work which we have done but not yet completed, we can show that the vertebral bodies have to be displaced at least 50 per cent. before the capacity of the neural canal is cut down to such an extent that the cord is in danger. This is a most important anatomical point and I think this is something which has been overlooked in the problem of deformity in the vertebral column.

The other point that I would be interested to hear about is the problem of prolapsed intervertebral disc. In our pathological investigations we have never seen a prolapsed intervertebral disc causing paraplegia. This may be just that we have not looked at enough but we have looked at about 67 cases very carefully now at post-mortem and that does not show.

Mr. HARRIS (Great Britain). The answer to your question is that that particular patient had a normal-looking spinal column as seen in the X-rays. The spinal canal was probably of normal diameter. The point that I made, and have made previously, 
is that the pathology there is an internal deformity: there is a deformity of the spinal theca with prolapse of the roots and damage to the roots. They become adherent and there is progressive damage to the roots. The patient did not, as one would expect, seeing this pathology, make any important degree of recovery. We freed these roots and the patient was put on hydrocortisone, but any recovery was not of value to him.

Chairman, Professor AdLeR. As far as the last remark of Dr. Bedbrook's is concerned, I would say that we have seen paraplegia with disc prolapse. We have seen two or three cases like this.

Professor JochHeIM (Germany). Running a very small Centre, I apologise for having more questions than answers. I should like to ask Mr. Harris what is the indication and the best time for myelography? As we have an oedema at the beginning of traumatic cord lesions, is myelography indicated or should it be done a couple of days later?

Mr. Harris (Great Britain). Mr. Chairman, with due respect to the Meeting, I would really require about an hour or two to discuss the place for myelography in spinal cord lesions, including spinal trauma. I would say that there are definite indications and these are appreciated by people working on spinal cord problems, including spinal injury. It requires to be done in a special centre where there are these facilities and by a neuro-radiologist working closely with the clinician. I think I could not extend this.

Dr. RossIER (Switzerland). I should like to make two points. I have noticed, in quite a few cases, that especially at the dorso-lumbar juncture, even if leaving the patient lying supine in hyperlordosis, as Sir Ludwig treats his patients when there is some dislocation of the vertebra, there was a secondary kyphosis after three to four months of supine position later on.

Secondly, I would stress the fact that people who are dealing with spinal cord injuries ought, perhaps, to consider much more air-myelography than myelography with opaque substances. In cervical lesions, in particular, the technique is difficult when using Crutchfield tongs or any other type of head traction, for one has to tilt the patient head-down and has to increase the hyper-lordosis of the cervical spine. I do not think this is indicated in cord trauma. Now, this is not at all necessary when using airmyelography and we have had good experience in Geneva for nearly three years in this field without any complications at all. We found prolapsed disc and, moreover, we have been able to show direct compression by bony fragments.

Dr. KIRBY (Canada). The previous speaker has already touched on this point, but I would like to ask Mr. Harris a specific question about myelography in cervical cord injury.

In my experience, most cervical cord injuries produce a complete or virtually complete lesion and, although one achieves radiological alignment early in the course of treatment, very little recovery usually occurs. I would like to know specifically, Mr. Harris, what criteria you use when you say you should use myelography in order to exclude a cervical disc as a complicating factor in this traumatic lesion?

Mr. HARRIS (Great Britain). I gave these criteria in my paper and I gave illustrations on the slides.

Dr. Silver (Great Britain). The place and time-Jerusalem, I968, but, closing my eyes for a moment when Mr. Harris was speaking and subsequently, especially since the last question, I feel we are back at Stoke Mandeville, I967. We have, again, the advocacy of myelography for early investigation for cervical injuries.

I would just make one point, Mr. Harris-that in your figures given in the Spinal Injuries Symposium in Edinburgh there was a much higher mortality in the operated 
series of cervical injuries than in the non-operated cases. I would repeat the remarks that I made a year ago: In the cervical injuries, there is a high initial mortality from pneumonia or pulmonary embolus. Operation on the spinal cord is also fraught with dangers of ascending lesions, producing brain-stem lesions and turning an incomplete into a complete lesion.

Let us have stated, unequivocally, with all the indications for myelography and surgery, pre-operatively, post-operatively, the neurological degree of recovery. We have heard the speaker from Canada saying that he has not seen any improvement. We know from Dr. Bedbrook's magnificent paper, published two years ago, that the pathology of the injury is immediate: the damage takes place at the time of injury and any recovery from surgical decompression is doubtful.

Mr. KERR (Great Britain). We have just heard again this question of early operative treatment in cervical cord injury-and I would like to emphasise that one of the really important matters is whether the lesion is a complete lesion or an incomplete one.

Within the last two months, we have had two cases at Edenhall which strikingly illustrate the value of investigation and operation. One came from another centre, being treated conservatively. He had very good sensory sparing and he had good movement in his legs which improved. However, he had paralysis of both arms. Mr. Harris saw him, arranged a myelogram and did an anterior decompression. The patient, immediately post-operatively, found that he could function with his left hand and was thrilled.

The second case is one whom I saw only last week-he had been in our care and he had had a fusion done by one of Mr. Harris's colleagues. After the traction was removed, he had a collapse of the vertebrae at the fracture site and after two weeks he began to develop paraesthesias in his left side. Although he had been recovering motor power, he developed these paraesthesias and he was referred back immediately for further investigation: traction to be replaced and myelography. I do not know the result, but I will not be surprised at all if, on returning to Edinburgh, I hear that they found that there was compression on the cord and roots and that anterior decompression was indicated.

I, therefore, support strongly Mr. Harris's views that in an incomplete case one should watch very carefully, investigate very carefully with myelograms, if necessary, and carry out an anterior decompression if in an incomplete lesion there is pressure from the front.

Chairman. Thank you very much. I think that this is a problem, on the one hand of statistics and, on the other hand, of individual judgment. You cannot say that in every case it has to be like this: you cannot say the contrary. I would like to call on Sir Ludwig next.

Sir Ludwig Guttmann (Great Britain). I think we must really know what we are talking about. This is not a question of whether surgical treatment or conservative treatment: it is a question of when the one has to be done and when the other. Therefore, I would have been pleased if $\mathrm{Mr}$. Kerr had made these points a little clearer. It is quite clear from his remarks that the operation was done at a later stage. What we are talking about is the immediate treatment, and that is a completely different matter. I entirely agree with $\mathrm{Mr}$. Kerr that in an incomplete lesion one has to watch carefullybut the question is: how long does one have to watch carefully? No doubt, the longer you watch the less you will operate. . . (Laughter.) That is the opinion of very experienced orthopaedic surgeons and neurosurgeons. I think one should not disregard the experience of so many people of the past. I am still waiting for proper statistics of those surgeons who have operated immediately. I have been waiting for this for 25 years-and even longer. It is really high time that we considered this from a pure scientific and not from an emotional point of view. 
The second point is the question of what kind of investigation we should do. The most important one is certainly a proper neurological examination and this should be done in the acute cases every day, even twice a day. Then you will find that, by conservative treatment, incomplete lesions often improve. The improvement takes-and that applies not only to cervical lesions but to lesions at any level-quite a long time. Therefore, I am not convinced that, if after operation you get an improvement after two, three or four weeks, this is as a result of the operation.

With regard to the question of myelography, I can only warn from my own experience not to do a myelography in the acute stages. One might increase damage to the spinal cord, as we know, of course, from experience with spinal tumour diagnosis. If one operates later one can see a marked arachnoiditis which may have an important effect on the blood circulation of the spinal cord. This we have also to consider very carefully today. If you want to do a myelogram in traumatic lesions, I entirely agree with Dr. Rossier, do an air-myelogram. This is less irritating and, of course, the air is absorbed very quickly and completely.

Lastly, to comment upon Professor Beller's remarks, we always hear excellent reports about disc operations, but we do not hear, very often, about the effect of disc operations on people who go into the hospital complaining about low back pain, a myelogram is done, a disc or two is found, the operation is done most successfully-but, the patient leaves the hospital in a wheelchair. I have seen this kind of patient, and, therefore, I feel that we have to be very circumspect in our choice of taking the knife for patients suffering from disc disease.

Mr. Harris (Great Britain). The point one is making, Mr. Chairman, is that in a spinal injury service which includes all the specialties, neuro-radiology is represented. In our own service, we have been doing some four hundred myelograms last year, with radio-opaque material. Rightly done, I say this is not a problem. The opaque material is removed at the end of the procedure. Also, as Walter Kerr has mentioned, in such a service we are used to dealing with all sorts of spinal disturbances: 47 per cent. of our neurosurgery is on the spine. The cause of spinal cord disturbance is disc disease and now we have operated one hundred or more patients with cervical disc disease. Therefore, one can judge. We are not dealing with emotional problems or statistical problems -though statistics are important. They will come out in detailed reports and figures.

Chairman. There is no doubt that there are differences in approach, in opinionnot everything is proven. Particularly, as far as disc operation is concerned, I agree IoO per cent. with what Dr. Guttmann has said and in our hospital nobody is for operating discs just because of having pain.

Mr. McSweENey (Great Britain). I want to say how much we should appreciate Mr. Harris's endeavours. I know he is able to satisfy his own feelings and his own intelligence in the matter of early exploration and I believe that somebody has to keep on doing this-otherwise, to a certain extent, we would make very little progress.

\section{AFTERNOON SESSION}

Chairman, Sir Ludwig GuttmanN. I should like to thank Professor Adler for taking the Chair in this rather long morning session in such an able and kind way. The applause you received shows you far better than I can say in words how very much the audience has appreciated your Chairmanship.

We come now to the Afternoon Session, and I have great pleasure in asking Professor Adler to give his paper, which is on: Experience of Paraplegia following the Six-day War. 